\title{
Creating Scenarios and Guiding Learning in a Medical Simulation Center
}

\author{
Gregorio Mañeru Zunzarren ${ }^{1}$, Alfredo Rodriguez-Sedano ${ }^{2}$ \\ ${ }^{1}$ Simulation Center, Faculty of Medicine, University of Navarre, Pamplona, Spain; \\ ${ }^{2}$ Department of Education, University of Navarre, Pamplona, Spain. \\ Email: gomazu@unav.es, arsedano@unav.es \\ Received July $1^{\text {st }}$, 2011; revised July $15^{\text {th }}$, 2011; accepted July $20^{\text {th }}, 2011$.
}

\begin{abstract}
In this article we propose to address the importance of learning scenarios in a simulation center in graduate studies in Medicine. We will describe in detail the context in which this learning is developed. To do this, we need to reflect briefly on the contents that permit the configuration of these scenarios as teaching units, the objectives which should be commensurate with the level of training and experience of the students, the activities to develop and the means by which these are arranged, and, finally, the evaluation of the process. The development of this learning would not be possible without an activity guide, as a well as an evolution and debriefing stage.
\end{abstract}

Keywords: Scenarios, Competencies, Simulation, Debriefing, Innovation

\section{Creation of Learning Scenarios in Medical Simulation}

From the educational context in the teaching of medicine and nursing, simulation can be defined as "the technique by which to manipulate and control a virtual reality, fulfilling the steps and sequences necessary to stabilize, modify and reverse a phenomenon that directly and indirectly affects the normality of a biological, psychological and social being such as the human being.” (Lopez, 2007).

There a different classifications and methods of simulation, but as Vázquez-Mata y Guillamet-Lloveras (2009: p. 153) indicate, they should be distinguished by their practicality and complexity (see Table 1).

The effectiveness of learning environments depends less on the simulators or the facilities themselves than it does on the preparation of these and the guidance offered by the teacher. The effectiveness of simulation as a teaching methodology is demonstrated in numerous studies, more or less extensive, both in undergraduate education as in the period of residency training (Weller, 2004; Midik \& Kartal, 2010).

According to Özgür Tatli and Zeynep Tatli (2010: p. 1826) there are several benefits of using simulation in medicine education. The comparison of these benefits from the point of view of students, patients, education and institution is given in Table 2.

There are scenarios recreating traffic accidents, high-mountain rescues, responses to fires or medical assistance during catastrophes, to name a few examples. Learning scenarios that manage to re-create real or likely situations have a learning potential and the ability to achieve difficult goals that make them a very attractive means for the education and training in a student's personal, professional and social skills. They allow us to place ourselves in situations that we may never or very seldom find ourselves in, appealing to our knowledge and capacities for responding, taking action and making decisions
Table 1.

Practical classification of simulation-based training.

- Low complexity: based on simple models that permit the practice of isolated, basic skills (from learning anatomy to practicing basic skills such as the intubation of the airway).

- Intermediate complexity: brings together skills and require a certain level of integration between them. The paradigm is the acquisition of clinical skills, such as patient history and clinical examination,
Individual Training

Training in teams formulation of diagnostic approaches and writing prescriptions.

- High complexity: is based on the use of highly interactive technologies, i.e., ones that simulate reality, offer information and require active responses from the professional; allow training in difficult-toacquire psychomotor skills, such as virtual reality equipment for the simulation of endoscopies or laparoscopic surgery, or the management and treatment of arrhythmias.

- Low complexity: non-interactive or passive human mannequins that permit training in all methods of cardiopulmonary resuscitation, both in isolation and in conjunction with the mannequin; another example could be the initial exercises in extractions and the stabilization of injured patients.

- Intermediate complexity: workshops based on role playing to analyze situations, adverse events and medical errors, as well as situations of improvement.

- High complexity: Have two variants. The first focuses on team training in crisis situations (traumatic shock, myocardial infarction, intraoperative myocardia) and uses highly interactive human mannequins that reproduce cardiovascular and breathing functions with great fidelity, and all within a realistic scenario; in these simulations intensivists, emergency physicians, nurses, anesthesiologists and surgeons can participate simultaneously. The second option focuses on advanced surgical training requiring the full involvement of the surgical team, such as remote robotic surgery, which modifies all the classic surgical protocols. 
Table 2.

The Benefits of using simulations.

\begin{tabular}{|c|c|}
\hline $\begin{array}{c}\text { From Student's Point } \\
\text { of View }\end{array}$ & $\begin{array}{l}\text { Reduces Strain of Students } \\
\text { Repeating Opportunity } \\
\text { Increasing Clinical Experience } \\
\text { Instant Feedback } \\
\text { Opportunity of Using without Any Worry } \\
\text { about Safety } \\
\text { Opportunity of Testing all Possible Cases. } \\
\text { Making Students Think about His/Her } \\
\text { Own Performances } \\
\text { Minimization of the Possible Punishment } \\
\text { as a Result of Faulty Applications } \\
\text { Equality of Opportunity in Education } \\
\text { Learning by Doing } \\
\text { Opportunity of Training a Group } \\
\text { It can be Integrated to Curriculum } \\
\text { Mechanism for Repeated Applications } \\
\text { Facilitates Recalling } \\
\text { Opportunity of Practicing Applications } \\
\text { Related to Rare Diseases }\end{array}$ \\
\hline $\begin{array}{c}\text { From Patient's Point } \\
\text { of View }\end{array}$ & $\begin{array}{l}\text { Reducing Complication Rate } \\
\text { High Quality Service Complying with } \\
\text { Patient Rights } \\
\text { Patient Centred Approach }\end{array}$ \\
\hline $\begin{array}{l}\text { From Education and } \\
\text { Trainer's Point of View }\end{array}$ & $\begin{array}{l}\text { Reduces Complication Rate } \\
\text { Field Safety } \\
\text { Providing Training of High Attributions } \\
\text { to Larger Number of People in Shorter } \\
\text { Period } \\
\text { Consolidating Theoretical Knowledge } \\
\text { with Instant Practical Applications } \\
\text { Educational Environment Students Ac- } \\
\text { tively Participate } \\
\text { Offering Related Opportunities for Stu- } \\
\text { dent Field Competences }\end{array}$ \\
\hline $\begin{array}{l}\text { From Institution's Point } \\
\text { of View }\end{array}$ & $\begin{array}{l}\text { Low Cost (Rentability) } \\
\text { Lower Complication Rate } \\
\text { Education and Service of Higher Quality } \\
\text { Making Institution More Preferable } \\
\text { Labour Force of Higher Quality }\end{array}$ \\
\hline
\end{tabular}

under stress, preparing in some way in our subconscious a more or less automatic response should we find ourselves in similar situations in the future. Okuda (2009: p. 333) offers a decalogue of the features and applications that make the methodology of teaching via simulation scenarios effective (Table 3).

In general, medical scenarios are set in the context of a case study, or rather the model of competence-based learning (Martínez-Clares et al., 2008), and limited to a core activity of no more than 10 minutes. This is because there are so many parameters to be controlled in real-time situations that require extensive preparation and a countless number of evaluators that can meet all the variables. Limiting time helps to focus and sequence the activity in order to objectify and evaluate it. It should first be explained to the small group of four to six students what it is that will be done, what role each participant must assume, for which purposes and how the activity is going to develop. This will involve at least 10 minutes.

Finally, a debriefing or reflection should be conducted by the members of the group and the teacher at the end of the activity. The activity should be assessed in light of the stated objectives, in order to correct errors and evaluate the successes.

There are many questions to ask the teacher in shaping the scenario; for this reason it makes sense to be very specific
Table 3.

Features and uses of high-fidelity medical simulations that lead to effective learning.
1. Mechanism for Repetitive Practice
2. Ability to Integrate into a Curriculum
3. Ability to Alter the Degree of Difficulty
4. Ability to Capture Clinical Variation
5. Ability to Practice in a Controlled Environment
6. Individualized, Active Learning
7. Adaptability to Multiple Learning Strategies
8. Existence of Tangible/Measurable Outcomes
9. Use of Intra-Experience Feedback
10. Validity of Simulation as an Approximation of Clinical Practice

Note: The material for this table was taken from Issenberg et al. (2005) and Mc Gaghie et al. (2006).

about what it is you want to teach.

\section{Contents}

As in any training activity, four key elements must be distinguished in order to configure a learning scenario as a teaching unit. The first is the element that leads us to consider and reflect on what content you teach, what the degree of difficulty is, who is directing the activity and what previous knowledge the participants have. This also defines the kind of scenario to be created. All of the effort to ensure the student's learning and understanding the activity in order to develop particular skills and expertise that can afterwards be used independently, is pursues by contextual-izing it in scenarios that make it meaningful to the student. According to Delors (1996: p. 95), "it is no longer enough that each individual accumulates early in life a reservoir of knowledge which he may endlessly draw upon later. They must be able to take and use during life of every opportunity that presents itself to update, deepen and enrich the knowledge first learned and adapt it to a changing world”.

The European Qualifications Framework (EQF) European Council (2005) model appears to respond to some of the recommendations of the 1996 Delors Report. According to this report, learning throughout life makes it possible to organize the various stages of education to provide for a passage from one stage to another, and to diversify the paths through the system, while enhancing the value of each. "The concept of learning throughout life is the key that gives access to the twenty first century. It goes beyond the traditional distinction between initial and continuing education. It links up with another concept often put forward, that of the learning society, in which everything affords an opportunity of learning and fulfiling one’s potential” (Delors, 1996: p. 36).

The "lifelong learning" approach is in accordance with the widely accepted view that links each level and cycle of the education process with the achievement of objectives that the knowledge society demands (Kelly \& Morder, 2001; McLaughlin, 2005; Schriewer, 2000). Bently (1998) argues that the key resources for the generation of wealth for the future will be ideas, knowledge and creativity, not the land, labour, and physical materials of the past. In this perspective, the task is to increase individual responsibility for learning, with the aim of developing the competences that will allow each citizen to achieve lifelong employability in a dynamic and changing world (Cheetham \& Chivers, 1996; Kwiek, 2004; Smith \& 
Spurling 1999; Spencer \& Spencer, 1993). According to Guillén, Fontrodona, and Rodríguez (2007: p. 410), "ethical training may be considered as a key element in terms of individual responsibility development for a lifelong employability and its sustainability".

This premise is already of great importance with respect to education and student motivation, since in the activities carried out in the Simulation Center the motivational factor is achieved by constantly involving the students in an active way in an environment that is attractive for its semblance to reality. As a result, the teacher has a tool that permits placing demands on the students in order to help them achieve ambitious goals.

\section{Objectives}

The second element is very important because we need to establish what goals we intend to achieve, from what level we are starting and how we will have to plan scenarios in order to sequence our goals, as well as in what period of time we foresee completing them. Formal Learning Objectives for the course in September Must Be In Accordance with level of training and prior experience (Wyte et al., 1995; Ende et al., 1986).

Which errors are common to learning in each particular activity should be taken into account, which ones are most frequently committed in professional practice and why, what difficulties arise as students integrate and consolidate learning (how the student perceives the degree of difficulty and whether or not there are significant differences in the assessment of teaching with regard to these problems) and how the degree of acquisition of the desired objectives will be assessed.

According to Hofmann (2009: p. 2) "there appear to be many good reasons why simulations can be effective and efficient, e.g. that simulation provides the opportunity to do practice situations that seldom occur in practice or that expose the patient to unacceptable hazard. Some of these reasons are theoretical, hypothetical, or argumentative, as there is little empirical evidence of their importance”. Issenberg (2007) the literature on empirical studies on the outcome of simulation and have identified the features and uses of high-fidelity medical simulations that can lead to effective learning.

\section{Activities to Develop and Resources}

A third element is the one in which we evaluate what resources we have at our disposal to carry out the activity. The adequacy and timeliness of the activity to be developed is key; there must be no doubt that simulators will influence and guide the development of the scenario. We can create scenarios which, using standardized patients, basic simulators or even advanced simulators offer better feedback and allow us to manipulate different variables and parameters. It is not the same if we are able to rely on audiovisual recording media or if we do not have access to them. The instructor should have a high level of expertise in the use of simulators and the recording system so that he or she can focus on the principal activity of the scenario. If he or she does not, there should at least have staff that can be relied upon to assist in this task. Whether or not the center has facilities such as clinic rooms or operating rooms that permit the simulation of reality also influences the activity. The physical environment is a factor that helps to improve the intensity and realism of the scenario. "The High-fidelity simu- lations provide a controlled environment where learners can make, detect and correct errors without adverse consequences” (Hofmann, 2009: p. 2).

Among the preparatory work of the teacher, and it should not be regarded as being of lesser importance, is the essential responsibility of checking beforehand to ensure that each simulator to be used in the scenario and the recording system are functioning properly. It should also be verified that that are enough connections in the room and that all the consumables required by the scenario-gowns, gloves, masks, syringes, bag-masks, etc.- - are present and in good supply:

Once the content, objectives, activities and media to be employed have been established, how the extent to which they reach each of the goals will measured or evaluated should be defined and specified, as well as what means will be available to those who do not pass so that they can also achieve them.

\section{Evaluation}

Evaluation is the fourth element of the teaching process and for that reason we try to assess each student during the scenarios, so that the individual assessment is relative to achieving the objectives of the group, and should be clearly distinguished and differentiated. The scenarios allow the instructor to assess not only the students' competence relating to the technical and practical dimensions, it also permits the observation of personal skills such as communication style, interpersonal relationships, and leadership initiatives, ethical behavior and spontaneous reactions to the difficulties or successes of their peers or themselves, and so on. The instructor guiding the scenario should explain in advance what skills are being assessed and how they will be evaluated. It is also useful to have some well-defined indicators of the goals and stipulate in advance the system to be used in the evaluation, so as not to be influenced or conditioned by the subjective perception of the outcome of the scenario. The assessment should also be based on a framework different from traditional evaluation. Irigoin and Vargas (2002) graphically detail in Table 4 the difference between traditional assessment and the kind of competencybased assessment that this type of learning is based on.

Table 4.

Adapted from irigoin and vargas (2002).

\begin{tabular}{cc}
\hline TRADITIONAL EVALUATION & $\begin{array}{c}\text { COMPETENCY-BASED } \\
\text { EVALUATION }\end{array}$ \\
\hline Final Product & Continuous Process \\
Transmission of Knowledge & Personalized \\
Periodic & Knowledge Management \\
Objective testing & $\begin{array}{c}\text { Continuou Sprocess } \\
\text { The evaluator plays a passive role as } \\
\text { the administrator of the test. }\end{array}$ \\
$\begin{array}{c}\text { Focuses on parts of the curriculum } \\
\text { and takes place at the end of it. }\end{array}$ & $\begin{array}{c}\text { The evaluator plays an active role, } \\
\text { even as a trainer. } \\
\text { performance. }\end{array}$ \\
$\begin{array}{c}\text { Does not include knowledge beyond } \\
\text { the curriculum. }\end{array}$ & $\begin{array}{c}\text { Includes evaluation of previously } \\
\text { acquired knowledge from } \\
\text { experience. }\end{array}$ \\
\hline
\end{tabular}


The teacher should also assess his or her own performance and any events that influenced its development, the level of commitment and participation that has been achieved, the objectives that were not achieved as expected, etc., as this will significantly influence the desired quality of subsequent scenarios. We learn from experience if we reflect on it, not from the passage of time. Instructors will become guides and effectively aid students if they evaluate their own performance and ask themselves how they can improve as guides.

\section{Guiding the Activity}

As an observer, it is important to acquire the skill of making notes about and recording everything that occurs during the scenario and not to rely on one's memory, because this will speed up and significantly enrich the debriefing afterwards by allowing the reviewing and repetition of the key points or objectives of the activity. It is a good idea to have a rubric for each participant and a "check list” for each activity or objective. If it is possible to do it privately, students will be grateful as this is better than correction done anonymously or in a group. Errors are never the fault of a group of people or a team; they are personal, but the responsibility is shared. Depending on how the scenario unfolds and the group's participation, it may be interesting to include problems that require changes in leadership or result in increased participation of a student with one role or another. Naturally, the degree of knowledge of students to determine their ability to respond to problems that arise during development of activity, and our experience, we believe that the following pattern is useful as a guide to advanced students, a limited amount of data for decisionmaking, however, with student's early career, offer more data to help you succeed in making decisions. The degree of difficulty in the cases can be changed during the course of their development, provided this does not alter the objectives or create an unrealistic situation. Leading an activity is not exactly passive, but to avoid directing the activity, the instructor should be in the background: adapting to the students' indications and helping to maintain their attention, reporting unexpected development or modifications to the activity being conducted, because they provide information so that the students participating in the activity can make better decisions. Therefore, when creating scenarios teachers should assess the potential degree of difficulty in the use of simulators, and the programmed activities should always adapt to the participants' real possibilities of handling them, as well as the possible improvement and increase in knowledge and skills depending on time or the academic level of students. According to Issenberg (1999: p. 865), “The key element in the successful use of simulators is that they become integrated throughout the entire curriculum so that deliberate practice to acquire expertise over time is possible".

\section{The Role of the Instructor}

Since learning scenarios place students in the role of protagonist, the instructor will try to assume a non-intrusive role as a facilitator of learning, and to promote the involvement and initiative in students (Dieckmann, 2008). Is an important objective that the students achieve critical thinking and management skills (Wendy, 2004). This will therefore require some resources and relational skills so that the instructor's profile appears to be that of a close associate, cooperating and engaging in dialogue if needed, and not that of an evaluator or harasser.

In the event that the instructor's intervention becomes necessary, it is best to do so by asking open questions that refresh prior knowledge, or, if necessary, brief explanations to remind the students of the key objectives, and to clarify each participant's role. It is not the time to solve problems, or even to identify them.

\section{Evaluation and Debriefing of the Scenario}

Finally, it is time to evaluate and correct, once the activity concerned has been concluded, utilizing the recording of the activity made to prepare the debriefing (Mort, 2004; Rall, 2000). It's part of learning environments that has great value and perhaps its most important feature is as a means of training, as it aims to make the students self-assess and constructively critique the performance of their colleagues, the group as a whole and even the instructor. This requires an intense effort by the instructor to organize and plan his or her group's reflection on the activity being viewed once more in order to note and highlight the instructions, ideas or contributions that arose during the development of the activity. The physical orientation of the group is also important; the participants should all be able to see one another's faces. Once the group is seated, the guide should clarify with a brief explanation how the debriefing will take place and the time devoted to activity. It starts with a question to each component so that everyone feels challenged, asking them to present their views, suggestions or ideas on how to act according to their own roles and their assessment of the development, constraints and completion of the activity. Once the group has expounded upon its performance, it is time to offer food for thought as annotations and corrections collected by the instructor during the case, trying to highlight the successes and clarify doubts mistakes. The objectives and the extent of their achievement will be the assessment criteria both of the group and of each of its members. The model proposed for learning scenarios for pilots may be of interest (it is not for no reason that they are pioneers in the use of simulation as a teaching methodology), and their experiences can help to shed light on how to organize, conduct and complete a good debriefing (McDonnell, 1997). Closer to the context of education and medical training, Dieckmann's proposal can be very attractive for us (Dieckmann, 2009).

\section{Conclusion}

Students expect to receive the most comprehensive training possible, updated and adapted to their real needs as professionals, by means of scenarios that are both accessible and safe, while being as close as possible to real-life situations as possible. The scenarios allow the instructor to modulate or control the level of difficulty, and to assess individual and team participation. To the extent that we see a patient behind each disease, we find ourselves in an ethical context that cannot be renounced. It is an extraordinary way of ensuring that students have no doubts about the importance of always being attentive to patient safety, and in order to achieve this, the instructor must train them with great care and personal responsibility. The deeper question that arises is whether or not the methodology 
outlined in this paper may contain some of the keys to reducing the errors that occur in medical intervention To the extent that learning scenarios are a valid teaching methodology, they can help do that.

\section{References}

Bently, T. (1998). Learning beyond the classroom: Education for a changing world. London: Routledge Falmer.

Cheetham, G., \& Chivers, G. (1996). Towards a holistic model of professional competence. Journal of European Industrial Training, 20, 20-30. doi:10.1108/03090599610119692

Delors, J. (1996). Learning: The treasure within. Paris: UNESCO.

Dieckmann, P., Rall, M., \& Sadler, C. (2008). What competence do simulation instructors need? Minerva Anestesiol, 74, 277-281.

Dieckmann, P. et al., (2009). The art and science of debriefing in simulation: Ideal and practice. Medical Teacher, 31, e287-e294. doi:10.1080/01421590902866218

Ende, J., Pozen, J. T., \& Levinsky, N. G. (1986). Enhancing learning during a clinical clerkship: The value of a structured curriculum. Journal of General Internal Medicine, 1, 232-237.

doi:10.1007/BF02596189

European Council (22-23 March 2005). Presidency conclusions. Brussels: European Council.

Galindo, L. J. (2007). Simulation, a teaching aid for medical education. Salud Uninorte, 23, 79-95.

Guillén, M., Fontrodona, J. \& Rodríguez, A. (2007). The great forgotten issue: Vindicating ethics in the European Qualifications Framework (EQF). Journal of Business Ethics, 74, 409-423.

Hofmann, B. (2009). Why simulation can be efficient: On the preconditions of efficient learning in complex technology based practices. BMC Medical Education, 9, 1-6. doi:10.1186/1472-6920-9-48

Irigoin, M. Y., \& Vargas, F. (2002). Competencia laboral: manual, métodos y aplicaciones en el sector salud. Montevideo: CinterforOPS.

Issenberg, S. B., McGaghie, W. C., Petrusa, E. R. et al. (2005). Features and uses of high-fidelity medical simulations that lead to effective learning: A BEME systematic review. Medical Teacher, 27, 10-28. doi:10.1080/01421590500046924

Issenberg, S. B., \& Scalese, R. J. (2007). Best evidence on high-fidelity simulation: What clinical teachers need to know. The Clinical Teacher, 4, 73-77. doi:10.1111/j.1743-498X.2007.00161.x

Issenberg, S. B. et al. (1999). Simulation technology for health care professional skills training and assessment. Journal American Medical Association, 282, 861-866. doi:10.1001/jama.282.9.861

Kelly, J., \& Morder, W. (2001). The how and the why: Competences and holistic practice. Social Work Education, 11, 689-690. doi:10.1080/02615470120089861

Kwiek, M. (2004). The emergent European educational policies under scrutiny: The Bologna process from a central European perspective. European Educational Research Journal, 3, 759-776. doi:10.2304/eerj.2004.3.4.3

Martínez-Clares, P., Martínez-Juárez, M. Y., \& Muñoz-Cantero, J. M. (2008). Formación basada en competencias en educación sanitaria: Aproximaciones a enfoques y modelos de competencias. RELIEVE, 14, 1-23.

McDonnell, L. K., Jobe, K. K., \& Dismukes, R. K. (1997). Facilitating LOS debriefings: A training manual. Moffett Field, California: NASA Technical Memorandum, Ames Research Center.

McGaghie, W. C., Issenberg, S. B., Petrusa, E. R. et al. (2006). Effect of practice on standardised learning outcomes in simulation-based medical education. Medical Education, 40, 792-797. doi:10.1111/j.1365-2929.2006.02528.x

McLaughlin, T. (2005). The educative importance of ethos. British Journal of Educational Studies, 53, 306-325. doi:10.1111/j.1467-8527.2005.00297.x

Midik, Ö., \& Kartal, N. (2010). Simulation-based medical education. Marmara Medical Journal, 23, 389-399.

Mort, T. C., \& Donahue, S. P. (2004). Debriefing: The basics. In W. F. Dunn (Ed.) Simulators in critical care and beyond. Des Plaines: Society of Critical Care Medicine.

Okuda, Y. et al. (2009). The utility of simulation in medical education: What is the evidence? Mount Sinai Journal of Medicine, 76, 330343. doi:10.1002/msj.20127

Özgür, T., \& Zeynep T. (2010). Simulation applications in emergency medicine education. Procedia Social and Behavioral Sciences, 9, 1825-1829

Rall, M., Manser, T., \& Howard, S. K. (2000). Key elements of debriefing for simulator training. European Journal of Anaesthesiology, 17, Abstract.

Schriewer, J. (2000). World-system and interrelationship-networks: The internationalization of education and the role of comparative inquiry. In T. S. Popkewitz (Ed.), Educational knowledge: Changing relationships between the state, civil society, and the educational community (pp. 305-343). Albany, NY: State University of New York Press.

Smith, J., \& Spurling, A. (1999). Lifelong learning: Riding the tiger. London: Cassell.

Spencer, L. M., \& Spencer, S. M. (1993). Competence at work. New York, NY: John Wiley \& Sons.

Vázquez-Mata, G., \& Guillamet-Lloveras, A. (2009). El entrenamiento basado en la simulación como innovación imprescindible en la formación médica. Medical Education, 12, 149-155.

Weller, J. M. (2004). Simulation in undergraduate medical education: Bridging the gap between theory and practice. Medical Education, 38, 32-38. doi:10.1111/j.1365-2923.2004.01739.x

Wendy, C., \& Coates, M. D. (2004). An educator's guide to teaching emergency medicine to medical students. Academic Emergency Medicine, 11, 300-306. doi:10.1111/j.1553-2712.2004.tb02215.x

Wyte, C. D., Pitts, F., Cabel, J. A., Yarnold, P. R., Bare, A., Adams, S. L. (1995). Effect of learning objectives on the performances of students and interns rotating through an emergency department. Academic Medicine, 70, 1145-1146. doi:10.1097/00001888-199512000-00021 